\title{
A STUDY OF AN OPEN COIL ARC DYNAMO.
}

BY MILTON E. THOMPSON.

Of all the dynamo machines in use at the present day, perhaps the internal action of none is so little understood as that of the are lighting machines of the open coil armature class. Much concerning the regulation and general behavior of these machines seems utterly at variance with what one would naturally expect from a superticial examination of the design and construction, and it was with the idea of throwing some light on this seeming mystery that the investigation to be described was undertaken. In carrying out this work no attempt has been made to determine the efficiency of the dynamo, or to determine an answer to the question-Is the machine well suited for arc lighting? The vast numbers of these dynamos in daily use in all parts of the world is a practical answer which must carry more weight than any which might be suggested by a theoretical study of the machine. The experimental work of this investigation was carried out under the direction of Professor Nichols in the laboratories of Cornell University, during the past winter, by the writer, with the assistance of Mr. H. J. Hotchkiss and Mr. E. L. Morley, and due credit must be given to these gentlemen for any points of interest which may have been brought out by the investigation.

The object in view was to determine accurately. by taking instantaneous values throughout the revolution, the character of the external and internal currents and electromotive forces.

The capacity of the dynamo in question was about ten arc lamps of 1,200 c. $p$.

In order to carry out this work it was necessary to build a special commutating device for taking instantaneous values of 
current and potential. Professor Ryan was the first to introduce this method at Cornell, which is a modification of that described by Joubert in $1881,{ }^{1}$ and since used by various observers in alternate current work. The device he used was described at length in a paper read before the Institute ${ }^{2}$ on the 17th of December, 1889. The device consisted essentially of a metal tongue mounted upon the shaft of the dynamo and revolving with it, and making contact once each revolution with a small metal spring mounted upon an arm whichwas so arranged that it could be revolved about an axis coincident with that of the armature of the dynamo and secured in any desired position. By properly adjusting the position of the arm carrying this spring, contact could be made to take place between the spring and the tongue at any desired point of the entire revolution of the armature.

Three sets of curves of exterior current and potential were taken with three different loads upon the machine, and three sets of curves of current and potential through a single coil were taken with the same loads. In order to keep the electromotive force as nearly constant as possible, and prevent variations while a set of observations were being taken, the machine was loaded with a german-silver resistance. The loads consisted of about 20, 50, and $80 \mathrm{ohms}$ respectively, and were equivalent to about three, six and ten arc-lamps. The current for all loads was supposed to be practically constant, and an ammeter placed in the circuit showed but little variation from the normal current of 6.5 amperes. A condenser and ballistic galvanometer were used for making the measurements, and Fig. 1 shows a diagram of the connections of the dynamo and also of the measuring apparatus. Referring to the diagram, $\mathrm{A}$ is the armature, $\mathrm{FF}$ the field coils, $\mathrm{m}$ the regulator magnet, $\mathrm{c}$ the controller magnet, and $r$ the carbon resistance used to prevent excessive sparking at the contacts $k ; \mathrm{P}$ is the positive terminal of the machine and $\mathrm{N}$ the negative, $\mathrm{R}$ is the german silver resistance which constituted the load for the dynamo, and $i$ is a resistance of about one ohm placed in the circuit to serve as a basis for the current measurements. LL and ss are the brushes of the dynamo, which bear against the three segments of the commutator, as shown in the diagram ; $\mathrm{D}$ is a condenser, $\mathrm{K}$ a discharging key, and $J$ a small spring switch; $G$ is a ballistic galvanometer, through which the condenser was discharged, and $\mathrm{T}$

1 Joubert; Etudes sur les Machines Magneto-Electriques; Annales de l'Ecole Normale-Superieur, 10, 46 pp., 1881.

2 Transactions, vol. vii, p. 3. 
is a shunt box for regulating the throw of the galvanometer and bringing it within proper limits. From the negative terminal of the machine, $\mathrm{N}$, runs a wire to the commutating device, $c s$, and from that to the switch, J. From the positive terminal, $\mathrm{P}$, and the binding post, B, run wires to $f$ and $g$ of the switch, $f g h$, as shown. From $g$ of this switch runs a wire to the discharging key, $\mathbf{k}$.

Before describing the methods of taking the measurements, it

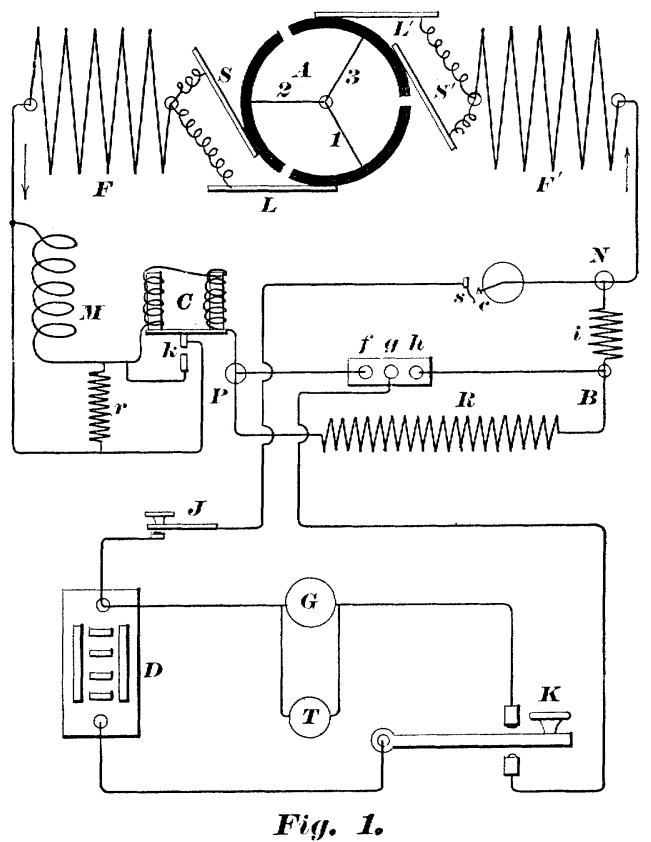

may be well to review briefly the operation of the dynamo and its regulation so far as is apparent from an outside view. The current, leaving the armature through the brushes, $\mathrm{L}$ and $\mathrm{s}$, passes through the left field coil and thence through the regulator magnet and controller magnets to the positive terminal, $\mathrm{P}$, of the machine. Passing around through the external circuit. in this case the resistance, $\mathrm{R}$, the current returns to the machine by the negative terminal, $\mathrm{N}$, passes through the right field coil, $\mathrm{F}$, and through the brushes, $\mathrm{L}$ and $\mathrm{s}$, to the armature, thus completing the circuit. The regulation of the machine is effected as follows: The controller magnet $\mathrm{c}$ is so adjusted, by means of a spring, that a 
current of 6.8 amperes will just raise the cords of the magnets and separate the contacts, $k$. This permits the current to flow through the regulator magnet, $\mathrm{s}$, and raises the regulator arm, thereby shifting the leading brushes, $\mathrm{L}$ and $\mathrm{L}^{\prime}$, forward, and the following brushes, s and s', backward, and thus reducing the potential furnished by the machine. The current is, of course, thereby diminished, and the cores of the controller magnet drop, closing the contacts, $k$, and thus short-circuiting and cutting out the regulator magnet. The regulator arm then falls, under the action of gravity, and the leading brushes being moved backward and the following brushes forward, the potential is raise 1 until the current increases sufficiently to once more open the contacts, $k$, and again cut in the magnet of the regulator. The controller magnet acts simply as a relay, and is continually cutting the regulator in and out of the circuit, and in this way the current is maintained constant, regardless of the varying conditions of the external cireuit.

During these experiments the regulator was allowed to act just as in ordinary practice, but each load was constant and practically non-inductive. Three sets of curves of external current and potential were taken and the measurements were made in the following manner: The commutating device, $c s$, being secured in a fixed position, $f$ and $g$ were connected. The discharging key, $\mathrm{k}$, being then depressed, switch $J$ was then closed and in a few seconds the condenser became charged with the difference of potential existing between the terminals of the dynamo at the particular point of the revolution of the armature represented by the position of the commutating device. Switch $J$ being then opened, the discharging key, $\mathrm{k}$, was allowed to rise, and the condenser was thus discharged through the galvanometer, $\mathrm{G}$, causing a deflection which was duly noted. The connections of the switch. $f g h$. were then changed so that $g$ and $h$ were joined, and in this way the condenser was charged with the difference of potential existing between the points $\mathrm{B}$ and $\mathrm{N}$ of the external circuit, at the same point of the revolution as the first reading. The condenser was then discharged through the galvanometer and the deflection noted as before.

After moving the contact spring, $s$, forward ten degrees, the measurements just described were repeated, and so on until the contact had been moved entirely around the circle.

The condenser and galvanometer being properly calibrated, it 
was an easy matter to calculate from the data obtained as above, the difference of potential between the terminals $\mathrm{P}$ and $\mathrm{x}$, and between $\mathrm{B}$ and $\mathrm{N}$, at 36 points of the revolution of the armature. The resistance between $\mathrm{B}$ and $\mathrm{N}$ being known, the current was readily determined from the fall of potential. The results of these measurements are given in Table I and are shown graphically in Fig 3 and will be referred to later.

After taking curves of the exterior potential and current, the apparatus was arranged for measuring the potential and current in a single coil of the armature. Coil number 2 was selected

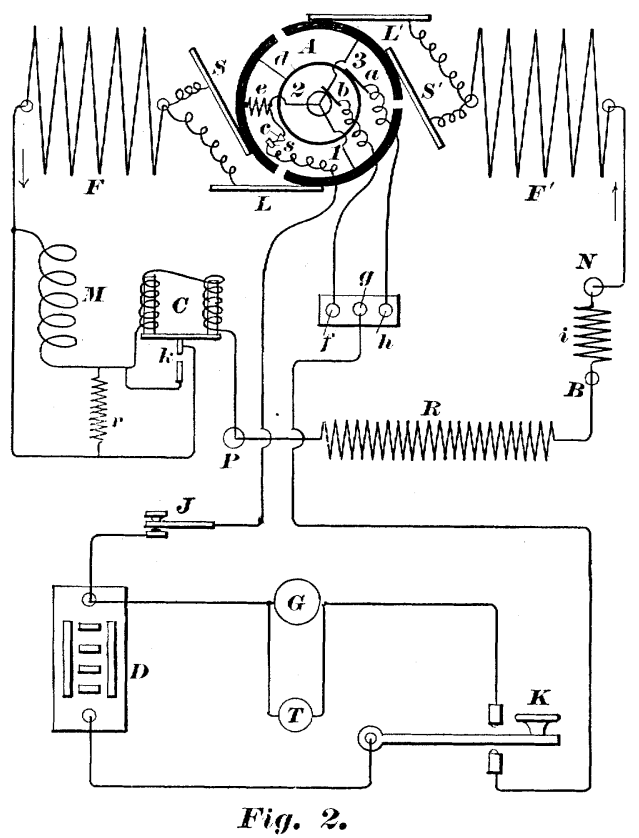

as likely to present results nearest the average of all three of the coils, and the apparatus was arranged as shown in Fig. 2. The circuit of the dynamo and its loads were exactly as for the first measurements, and the connections of the measuring instruments were as shown in the diagram. Referring to Fig. 2, $a$ is a small brush which bears against a ring $d$ secured to the commutator but carefully insulated from it. This ring is connected to the commutator bar of coil number 2, and thus gives metallic connection with this bar at all points of the revolution. A small brush $b$ bears against a similar ring wound round the 
armature shift but insulated from it. This last ring is connected to the three inner ends of the three coils, and thus a continnous contact is made with these ends. The outer end of coil number 2 was disconnected from the commutator bar and a small non-inductive resistance $e$ was inserted between the end of the coil and the bar. The junction of the coil and the resistance $e$ was connected to the tongue $c$ which revolved with the armature shaft. Once during each revolution the tongue $\theta$ made contact with the small spring s, from which a wire ran to the switch $J$ and thence to one terminal of the condenser $D$. Wires ran from brushes $a$ and $b$ to the switch $f g h$, and from this switch a wire ran to the discharging key $\mathrm{k}$, as shown on the diagram. When $g$ and $h$ were connected and keys $J$ and $\mathrm{k}$ depressed, the condenser was charged with the difference of

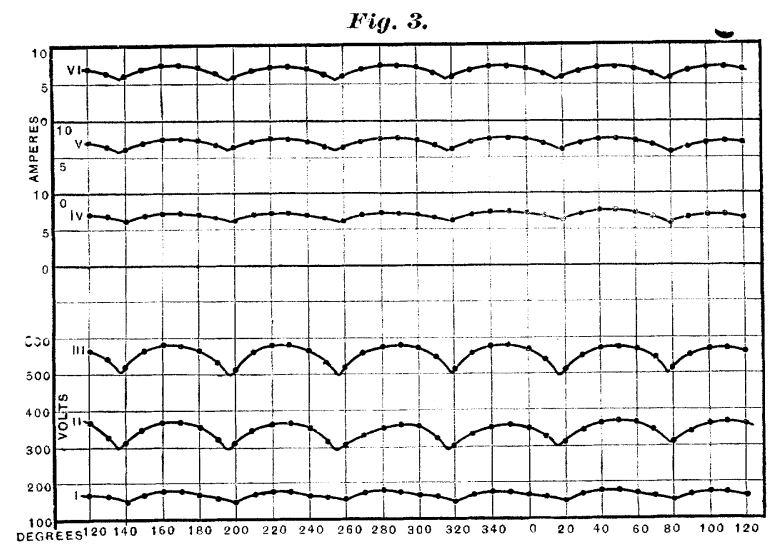

potential existing between the ends of coil 2 at the particular point of the revolution represented by the position of the contact spring $s$. The condenser being then discharged through the galvanometer, a measure of this difference of potential was. thus obtained. Switch $f g h$ was then changed so that $g$ and $h$ were connected, and measurements then taken with the condenser and galvanometer gave the difference of potential between the ends of the non-inductive resistance $e$, and from this the current in coil 2 was calculated. Readings were taken in this way at distances of five degrees apart all around the revolution and the results are given in Table II, and are shown plotted out in Figs. 4, 5 and 6 , three curves at three different loads being taken as before. It is not the purpose of the writer to go into the theories of cause and effect as exemplified in these 
curves, but to simply present them, calling attention briefly to some few of the more noticeable and interesting features connected with them.

Turning now to the results obtained, in Fig. 3, curve i represents the difference of potential at the terminals of the dynamo throughout the revolution under a light load, and curve iv is the corresponding current. Curve II is the potential for medium load and curve $\mathrm{v}$ the corresponding current, while curves III and vi represent the potential and current at full load. It will be noticed that the curves for medium and full load are practically alike while the curve for light load differs slightly in its character and is less symmetrical, and its minimum points occur slightly later than in the other curves. The curves of current and potential are practically alike, as might be expected since the self-induction of the external circuit was little or nothing. The

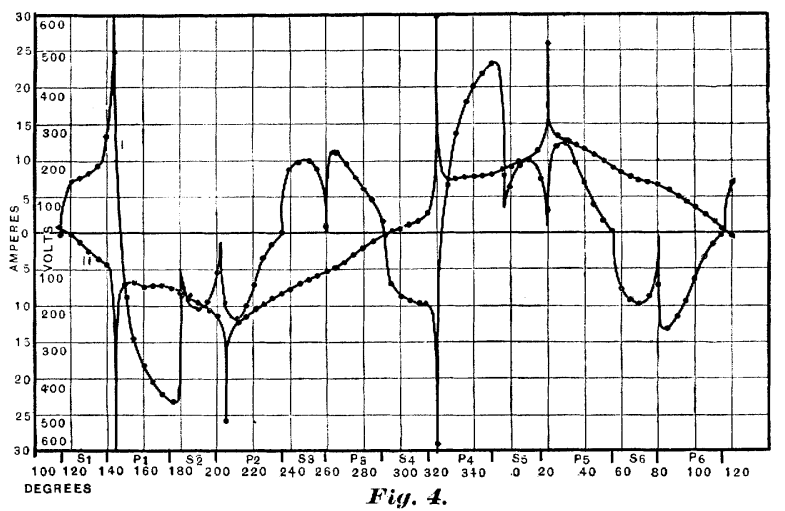

curves are all of them about such as wonld result from a closed coil armature with a six part commutator. It may be well to remark that in taking the observations for these curves, closer readings than are shown were taken near the minimum points, so as to be sure these points were correctly placed.

These curves show that the external current is continuous and much steadier and more uniform than is usually supposed.

Referring to Fig. 4, we find that the state of affairs in a single coil is quite different from that at the terminals of the dynamo. Curve I represents the difference of potential at the ends of the coil throughout the revolution, and curve II is the current in the same coil during the revolution. The curves shown in Fig. 4, were taken with a light load. Figs. 5 and 6 show curves taken 
with medium and with full loads. For some unknown reason it was found impossible to get accurate readings for the current at full load, and so no current curve is given in Fig. 6. It is proba-

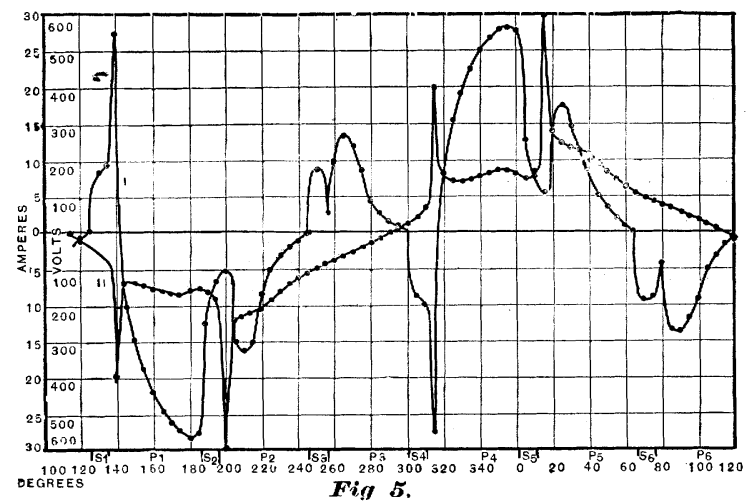

ble though, from the similarity of the current curves at light load and at medium load, that the current for full load differed very little from the other two.

It will be noticed that at all loads the potential changes sign no less than six times during the revolution and falls to zero, or almost to it, as often as twelve times, while the current reverses but twice during the revolution and for the most part goes through very gradual changes. At the bottoms of the figures are

Fiy. 6.

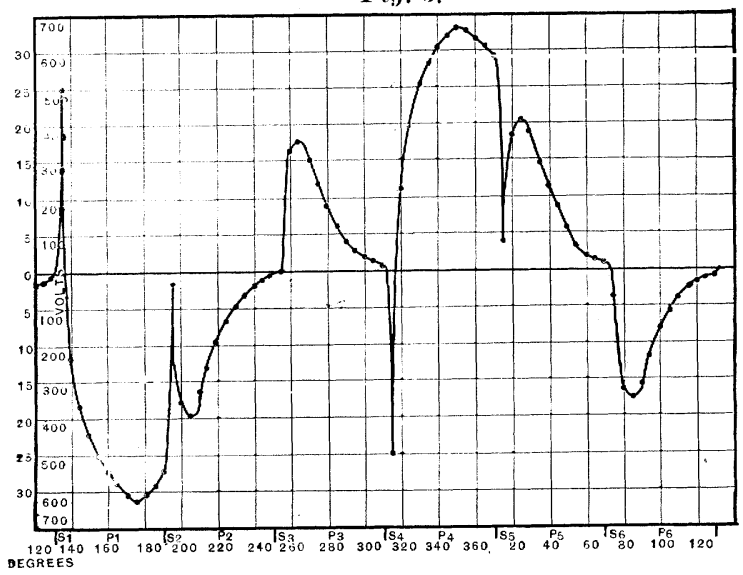

lines of spaces showing the positions of the armature during the part of the revolution represented by the curves above them. $s_{1}, s_{2}, s_{3}$, etc., are the periods of short circuit and $p_{1}, p_{2}, p_{3}$, etc., are 


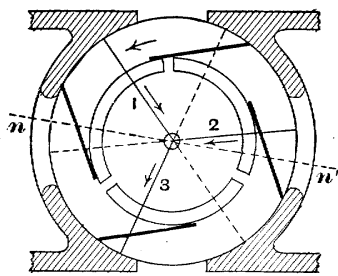

ivig. 10.

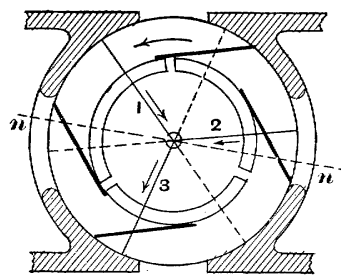

Fig. 14.

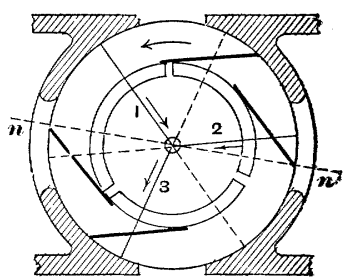

Fig. 18.

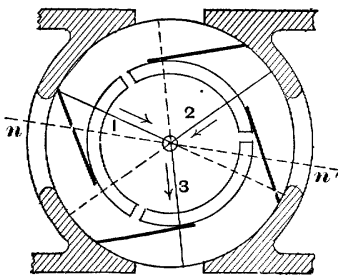

Fig. 11.

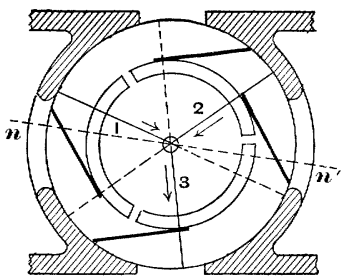

Fig. 15.

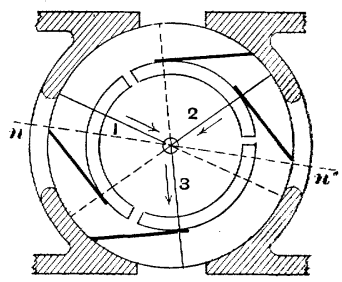

Fig. 19.

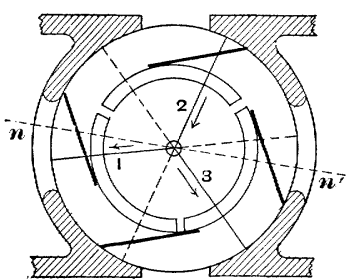

Fig. 12.

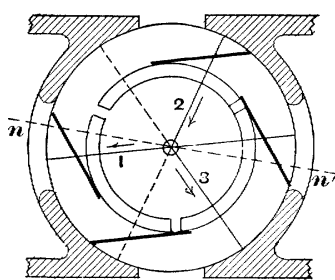

Fig. 16.

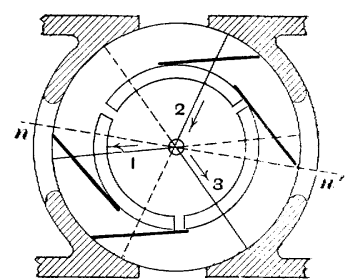

Fig. 20.

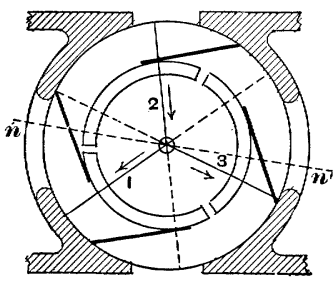

Fig. 13.

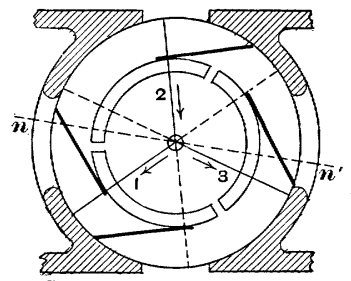

Fig. 17.

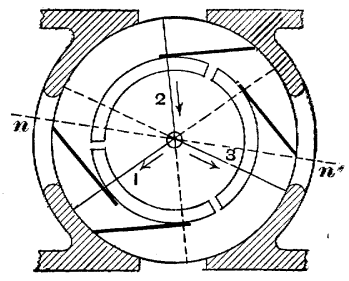

'Eig. 21. 
the periods during which two coils are usually supposed to be in parallel with each other and in series with the third coil. There are six periods of each kind in the course of each revolution. Figs. 10, 14 and 18 represent the relative positions of commutator and brushes at the three different loads during the parts of revolution shown at $\kappa_{1}$ For the light load this period is about $25^{\circ}$; for the medium load about $10^{\circ}$, and for full load not more than $1^{\circ}$. The periods shown are not the actual, but the cpparent periods of short circuit as it would seem to be from the positions of the commutator and brushes. The actual periods of short circuit are somewhat longer, owing to the conductivity of the spark, and last until the spark is blown out. The exact point of the revolution represented by figs. 10,14 and 18 , is the point $130^{\circ}$, as marked below the curves. Figs. 11, 15 and 19 represent the positions of the brushes and commutator for the parallel periods

Fig. $\%$.

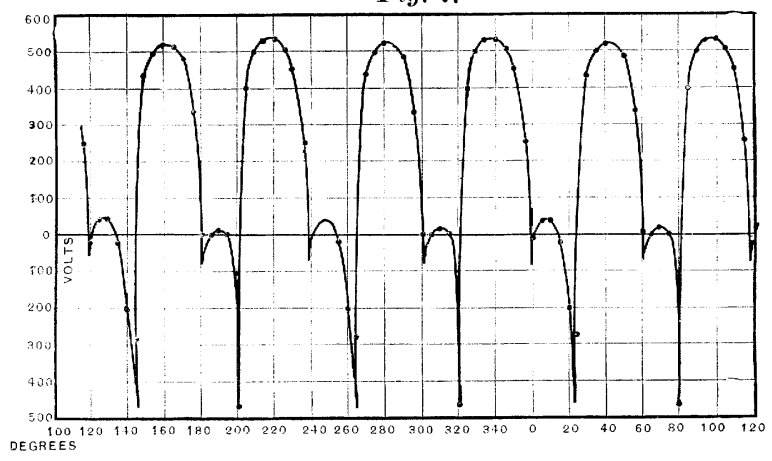

$p_{1}, o r$, to give the exact position shown, $160^{\circ}$. Figs. 12,16 and 20 represent the second short circuit period, $s_{z}$, or $190^{\circ}$, and Figs 13 , 17 and 21 show the second periods of parallelism, $p_{2}$, or $220^{\circ}$. In all of these figures the relative positions of the coils and poles of the dynamo are also shown, the coils being numbered $1,2,3$, just as they are on the dynamo. During the entire period represented by each four figures as above, the armature has turned through $120^{\circ}$, or one third of the revolution, and if we now consider the position of coil 2 changed to that of coil 1 in each figure, our figures will then represent the next third of the revolution. If coil 3 is supposed to occupy the position of coil 1, we shall then have the remaining third of the revolution.

It will be noticed that the more sudden and violent changes of potential occur just as the spark is forming and being broken at the front end of the commutator bar. 
In examining these curves of potential it should be remembered that they represent the difference of potential at the ends of the coil and not the w. x. F. developed in the coil during the revolution. The sudden and marked changes in current which are shown at certain points of the current curves, are selected from a number of readings which showed great variation. In some cases the reading had an opposite value from that shown in the curve, and it seems probable, that all things considered, the average value of these points should be very little, if any, different from the others, and the whole should form a smootlı curve without any very sudden changes. In Figs. 10 to 21 , the arrow shows the direction of the current in each coil during that particular part of the revolution represented by the figure. In each of these figures a neutral line $n u^{\prime}$ is shown, in passing which the current in each coil becomes zero and reverses. It

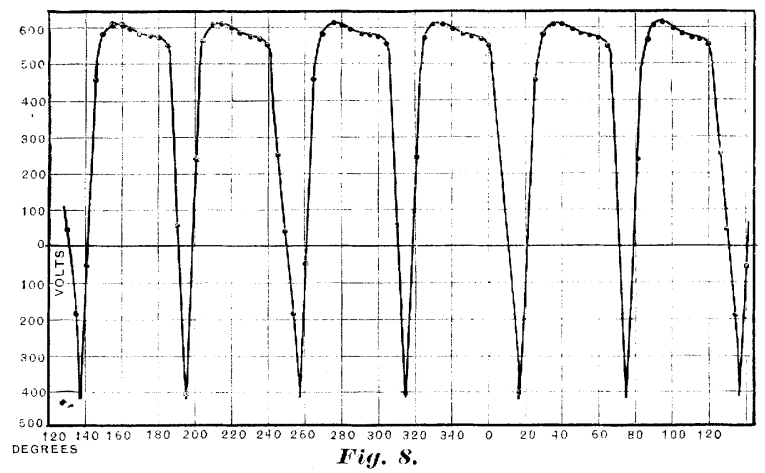

will be noticed that the direction of the currents in the various coils for the so-called periods of parallelism and short-circuit is quite different from what would be naturally expected and from what has been supposed to be the case in most of the descriptions of the action of this machine. For instance, in Fig. 11, we have the current in coil 1 flowing toward the junction of the three wires, showing that a current is flowing from the junction through coil 3 to the left pair of brushes and back through coil 1 to the junction again, or in other words that coils 1 and 3 are short-circuited upon each other. This state of affairs continues, with the light load, until commutator bar ? touches the right following brush and short-circuit period $x_{2}$ commences. Thus it will be seen that there is no instant during the so-called parallel period when coils 1 and 3 are in parallel and that the actual parallelism does not occur until after the beginning of the period of 
short-circuit. In the case of medium and full loads, however, it occurs at from $10^{\circ}$ to $20^{\circ}$ before the period of short-circuit. Another point worthy of notice is, that at the first instant of short-circuit, when the commutator bar just touches the following brush, there is no sudden increase of current as would be naturally expected, but the current in the short-circuited coils slowly and gradually increases until the short-circuit is broken by the blowing out of the spark, at which instant the current is a maximum in the coil whose commutator bar is opposite the sparking point, and in the other two coils it is about the same as the normal external current.

In Figs 7, 8 and 9 are shown curves of potential at the brushes, at the three different loads. These curves were obtained from the potential curves of Figs. 4, 5 and 6 , by adding together the

Fig. :.

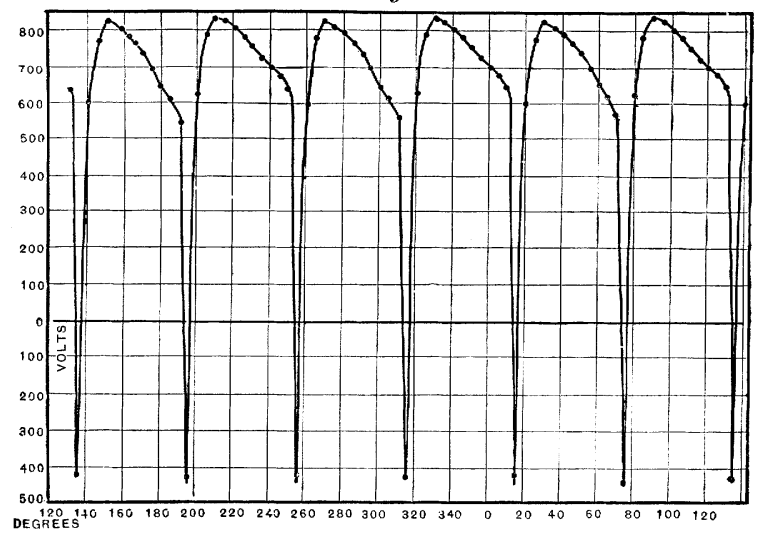

potentials of the three coils according to their relative positions, and thus obtaining the potential at the brushes. It will be noticed that at all loads the curves fall below zero six times during each revolution, and that the difference in area and consequent effective E. M. F., is obtained more by the widening out of the curves than by increase in height. This is what we ought to expect from the change in duration of the short circuit periods. A comparison of these three curves of potential at the brushes, with the three curves of potential at the terminals of the dynamo will give one a good idea of the remarkable steadying power which magnets such as the fields of this dynamo, exert upon an intermittent current. No further explanation is needed of the fact that this dynamo will not work as a separately excited machine. The whole set of curves will serve to illustrate some of the very re- 
markable effects of armature and field reactions and any one sufficiently interested to make a detailed study of them might possibly succeed in bringing out a number of curious and interesting, if not useful, results.

It is to be regretted that time did not permit the measurement of the exact electromotive force developed in a separate coil of the armature, as distinct from the difference of potential at the ends of the coil, and also the measurement of the changes of magnetism occurring in the fields of the dynamo. With the help of this additional data a very complete study of the internal actions of the machine might have been made, and possibly resu'ts might have been obtained which would throw useful light upon the interesting subject of armature reactions. The writer hopes at some time in the near future to make a further study of the machine in this respect and to present any further data obtained in this way as a supplement to this paper.

Corr əll University, May \&, 1891.

\section{TABLE I.}

\begin{tabular}{|c|c|c|c|c|c|c|}
\hline \multirow{3}{*}{ Degrees. } & \multicolumn{4}{|c|}{ Externat، Curves. } & & \\
\hline & \multicolumn{2}{|c|}{ Light Load. } & \multicolumn{2}{|c|}{ Medium Load. } & \multicolumn{2}{|c|}{ Full Load. } \\
\hline & Volts. & Amperes. & Volts. & Amperes. & Volts. & Amperes \\
\hline 120 & ז66 & 6.8 & 362 & 6.8 & $56 \mathrm{I}$ & 68 \\
\hline 130 & $\begin{array}{l}162 \\
162\end{array}$ & 7.0 & $3^{28}$ & $\begin{array}{l}6.0 \\
6.5\end{array}$ & 546 & $\begin{array}{l}6.0 \\
6.3\end{array}$ \\
\hline 140 & 150 & 6.2 & 308 & 5.9 & 516 & 5.9 \\
\hline $\mathrm{r} 50$ & 165 & 6.9 & 337 & 6.7 & $56 \mathrm{r}$ & 6.6 \\
\hline ז60 & 172 & 7.0 & 362 & 7.0 & 573 & 7.2 \\
\hline ז70 & 176 & 7.4 & 360 & 7.4 & 570 & 7.4 \\
\hline 180 & r68 & 6.8 & 352 & 7.0 & 563 & 6.8 \\
\hline 190 & 158 & 6.6 & 316 & 6.4 & 526 & 6.3 \\
\hline 200 & ז 46 & 6.1 & 294 & 6.0 & 509 & 5.9 \\
\hline 210 & I68 & 6.9 & $33^{6}$ & 6.9 & $5^{6 \mathrm{r}}$ & 6.8 \\
\hline 220 & I 78 & $7 \cdot 4$ & 352 & 7.0 & $57 \mathrm{r}$ & 7.4 \\
\hline 230 & 176 & 7.2 & 360 & $7 x$ & 566 & 7.0 \\
\hline $\begin{array}{r}240 \\
250\end{array}$ & $\begin{array}{l}162 \\
160\end{array}$ & 6.6 & 350 & 7.0 & 553 & 6.6 \\
\hline $\begin{array}{l}250 \\
260\end{array}$ & 160 & 6.3 & 308 & 6.3 & 524 & 6.1 \\
\hline $\begin{array}{l}260 \\
270\end{array}$ & $\begin{array}{l}150 \\
\text { I } 88\end{array}$ & $\begin{array}{l}\text { b.I } \\
6.8\end{array}$ & $\begin{array}{l}305 \\
336\end{array}$ & $\begin{array}{l}6.2 \\
6.7\end{array}$ & $\begin{array}{l}516 \\
558\end{array}$ & $\begin{array}{l}5.9 \\
6.8\end{array}$ \\
\hline 280 & $\begin{array}{l}178 \\
778\end{array}$ & 7.2 & 350 & $\begin{array}{l}7.7 \\
7.0\end{array}$ & $\begin{array}{l}550 \\
568\end{array}$ & $\begin{array}{l}7.0 \\
7.2\end{array}$ \\
\hline 290 & ז70 & 7.0 & 354 & 7.5 & 566 & 7.0 \\
\hline 300 & 162 & 6.8 & $\begin{array}{l}354 \\
352\end{array}$ & 7.0 & ${ }_{5} 6 \mathrm{x}$ & 6.8 \\
\hline 3 זо & 160 & 6.5 & $3^{1} \mathbf{I}_{3}$ & 6.4 & 540 & 6.3 \\
\hline 320 & $\mathrm{r}_{4} 8$ & 6.2 & 308 & $\begin{array}{l}5.8 \\
5.8\end{array}$ & $\begin{array}{l}340 \\
505\end{array}$ & $\begin{array}{l}5.9 \\
5.9\end{array}$ \\
\hline $33^{\circ}$ & 168 & 6.9 & 334 & 6.5 & 554 & 6.6 \\
\hline $34^{\circ}$ & 176 & 7.4 & 347 & 7.0 & $57 \mathrm{I}$ & $7 \cdot 4$ \\
\hline $35^{\circ}$ & 174 & 7.4 & 352 & 7.2 & 568 & 7.2 \\
\hline 0 & 166 & 6.8 & 352 & 7.1 & 565 & 6.8 \\
\hline 10 & 162 & 6.7 & 326 & 6.4 & 536 & 6.6 \\
\hline 20 & $\begin{array}{l}148 \\
-68\end{array}$ & $\begin{array}{l}6.1 \\
6.8\end{array}$ & 308 & $\begin{array}{l}6.0 \\
68\end{array}$ & 495 & 5.7 \\
\hline 30 & 168 & 6.8 & $\begin{array}{l}342 \\
360\end{array}$ & 6.8 & 546 & \\
\hline 40 & $\begin{array}{l}176 \\
578\end{array}$ & 7.2 & $\begin{array}{l}360 \\
365\end{array}$ & 7.2 & $\begin{array}{l}563 \\
568\end{array}$ & 7.0 \\
\hline $\begin{array}{l}50 \\
60\end{array}$ & $\begin{array}{l}178 \\
768\end{array}$ & $\begin{array}{l}7.4 \\
6.9\end{array}$ & $\begin{array}{l}365 \\
362\end{array}$ & $7 \cdot 3$ & $\begin{array}{l}568 \\
56 \mathrm{r}\end{array}$ & $\begin{array}{l}7.2 \\
6.8\end{array}$ \\
\hline 70 & 160 & 6.6 & 345 & 6.7 & 546 & $\begin{array}{l}.0 .0 \\
6.3\end{array}$ \\
\hline 80 & 152 & 6.3 & 305 & 5.9 & $5 \times 4$ & \\
\hline $9 \circ$ & 162 & 6.6 & 336 & $\begin{array}{l}3.9 \\
6.3\end{array}$ & 546 & $\begin{array}{l}3.9 \\
6.8\end{array}$ \\
\hline ToO & 176 & $7 \cdot 3$ & 360 & 7.0 & 568 & \\
\hline IIO & 174 & 7.2 & $3^{65}$ & 7.2 & 568 & 7.2 \\
\hline
\end{tabular}


TABLE II.

\begin{tabular}{|c|c|c|c|c|c|c|}
\hline \multicolumn{7}{|c|}{ Internat, Curves. } \\
\hline \multirow{2}{*}{ Degrees. } & \multicolumn{2}{|c|}{ Light Load. } & \multicolumn{2}{|c|}{ Medium Load. } & \multicolumn{2}{|c|}{ Full Load. } \\
\hline & Volts & Amperes. & Volts. & Amperes. & Volts & A mperes. \\
\hline 120 & $140+$ & $.28-$ & $13-$ & $1.3 \mathrm{I}$ & $33-$ & \\
\hline 125 & 149 & 1.43 & o & 2.2 & 24 & \\
\hline 130 & 160 & $2.5^{6}$ & $170+$ & 3.0 & Ij & \\
\hline $\begin{array}{l}\text { I35 } \\
\text { I40 }\end{array}$ & 173 & $3 \cdot 71$ & 190 & 3.25 & $500+$ & \\
\hline $\begin{array}{l}\text { I } 40 \\
\text { I } 45\end{array}$ & $\begin{array}{l}268 \\
500\end{array}$ & 4.28 & 549 & 15.0 & $\begin{array}{l}232 \\
368\end{array}$ & \\
\hline $\begin{array}{l}\text { I45 } \\
\text { I50 }\end{array}$ & $\begin{array}{l}500 \\
180-\end{array}$ & $\begin{array}{r}30.0 \\
7.4\end{array}$ & I. $\cdot 7-$ & 6.5 & $\begin{array}{l}368 \\
445\end{array}$ & \\
\hline 155 & 290 & $\begin{array}{l}7 \cdot 4 \\
7 \cdot 0\end{array}$ & $\begin{array}{l}292 \\
374\end{array}$ & $\begin{array}{l}7.0 \\
7.2\end{array}$ & $\begin{array}{l}445 \\
503\end{array}$ & \\
\hline 160 & $3^{68}$ & 7.5 & $\begin{array}{l}374 \\
445\end{array}$ & $\begin{array}{l}7.2 \\
7.6\end{array}$ & 543 & \\
\hline 165 & 409 & 7.5 & 490 & 7.85 & 580 & \\
\hline $\begin{array}{l}170 \\
175\end{array}$ & $44^{1}$ & 7.6 & 520 & 8.15 & $61_{3}$ & \\
\hline $\begin{array}{l}175 \\
180\end{array}$ & 464 & $7 \cdot 7$ & 549 & 8.5 & 627 & \\
\hline $\begin{array}{l}180 \\
185\end{array}$ & $\begin{array}{l}173 \\
700\end{array}$ & 7.75 & $5^{60}$ & $7 \cdot 7$ & 607 & \\
\hline $\begin{array}{l}185 \\
190\end{array}$ & $\begin{array}{l}190 \\
202\end{array}$ & 9.2 & 555 & $7 \cdot 3$ & $5^{82}$ & \\
\hline 195 & $\begin{array}{l}202 \\
190\end{array}$ & $\begin{array}{l}9.75 \\
10.5\end{array}$ & 255 & 8.0 & 545 & \\
\hline 200 & IIO & & 130 & $9 \cdot 3$ & 37 & \\
\hline 205 & rgo & $\begin{array}{l}\text { Ir.1 } \\
26.0\end{array}$ & $\begin{array}{l}107 \\
296\end{array}$ & $\begin{array}{l}30.0 \\
12.1\end{array}$ & $\begin{array}{l}302 \\
395\end{array}$ & \\
\hline 210 & 235 & 12.7 & $3^{20}$ & Ir. 3 & $\begin{array}{l}395 \\
3^{25}\end{array}$ & \\
\hline 215 & 202 & I2.0 & 295 & I I.I & $26_{3}$ & \\
\hline 220 & 145 & Io. 6 & $17^{\circ}$ & 10.3 & I95 & \\
\hline 225 & 65 & Io.o & 105 & 9.22 & 137 & \\
\hline $23^{\circ}$ & 35 & $9 \cdot 3$ & $5^{1}$ & 8.1 & 95 & \\
\hline 235 & 3 & 8.5 & 24 & 7.1 & 70 & \\
\hline $24^{\circ}$ & $175+$ & $7 \cdot 75$ & 9 & 6.3 & 40 & \\
\hline 245 & 192 & 7.0 & $\stackrel{\circ}{\circ}$ & 5.6 & 27 & \\
\hline 250 & 198 & 6.5 & $181+$ & 4.96 & I8 & \\
\hline 255 & 178 & 6.0 & 50 & 4.25 & o & \\
\hline 260 & 233 & $5 \cdot 5$ & 199 & 3.68 & $333+$ & \\
\hline 265 & $22 \mathrm{I}$ & $4 \cdot 7$ & 269 & 3.12 & 350 & \\
\hline 270 & I95 & 4.0 & 237 & 2.7 & 303 & \\
\hline 275 & I55 & 3.0 & 178 & 2.2 & 232 & \\
\hline 280 & 120 & $2 \cdot 3$ & 80 & 1.5 & I 70 & \\
\hline 285 & 90 & I. 3 & 55 & 1.0 & II9 & \\
\hline 290 & 35 & $\cdot 5$ & 35 & .2 & $7^{6}$ & \\
\hline 295 & $\mathrm{I}_{4} \mathrm{O}-$ & .28 & 20 & $.5+$ & $5 \mathrm{I}$ & \\
\hline 300 & $175-$ & $.75+$ & $6+$ & $1.31+$ & $33+$ & \\
\hline $3^{\circ} 5$ & 184 & $\mathrm{x} .25$ & $174-$ & 2.18 & 30 & \\
\hline $3^{10}$ & $19^{\circ}$ & 1.75 & I95 & $3 . c 6$ & I5 & \\
\hline $3^{15}$ & I93 & 2.6 & 549 & 20.0 & $5^{00-}$ & \\
\hline 320 & 580 & $3^{\circ}$ & I5ot & 7.6 & $220+$ & \\
\hline 325 & $149+$ & $7 \cdot 2$ & 304 & 7.0 & 390 & \\
\hline 330 & 276 & $7 \cdot 7$ & $3^{80}$ & 7.0 & 505 & \\
\hline 335 & 362 & 7.6 & $45^{\circ}$ & $7 \cdot 3$ & 555 & \\
\hline $34^{\circ}$ & 408 & 7.64 & $5^{\circ 2}$ & $\begin{array}{l}7.6 \\
7.85\end{array}$ & 606 & \\
\hline $\begin{array}{l}345 \\
350\end{array}$ & $\begin{array}{l}437 \\
462\end{array}$ & $\begin{array}{l}7.78 \\
8.0\end{array}$ & $\begin{array}{l}535 \\
558\end{array}$ & $\begin{array}{l}7.85 \\
8.5\end{array}$ & $\begin{array}{l}641 \\
656\end{array}$ & \\
\hline $\begin{array}{l}350 \\
355\end{array}$ & $\begin{array}{l}402 \\
173\end{array}$ & $\begin{array}{l}8.0 \\
8.6\end{array}$ & $\begin{array}{l}558 \\
566\end{array}$ & $\begin{array}{l}8.5 \\
8.6\end{array}$ & 652 & \\
\hline o & 122 & 9.2 & 555 & 7.7 & 631 & \\
\hline 5 & I9O & 9.9 & 256 & $7 \cdot 3$ & 610 & \\
\hline Io & 199 & I0. 5 & I55 & 8.3 & 579 & \\
\hline$I_{5}$ & I 49 & $1 \mathrm{I} .4$ & 107 & 30.0 & 74 & \\
\hline 20 & 60 & 0 & 275 & 13.5 & $3^{68}$ & \\
\hline 25 & $24 \mathrm{I}$ & $\mathrm{I}_{3}$ & 347 & I2.2 & 407 & \\
\hline 30 & 247 & I 2.7 & 288 & II. 6 & $3^{80}$ & \\
\hline 35 & 199 & 12.3 & 224 & II. 2 & 285 & \\
\hline $4^{\circ}$ & 140 & II. 7 & 161 & Io. 6 & 235 & \\
\hline 45 & 83 & (1). 8 & 107 & 9.22 & I67 & \\
\hline 50 & $3^{6}$ & 9.96 & 60 & 8.22 & II3 & \\
\hline $\begin{array}{l}55 \\
60\end{array}$ & $\begin{array}{r}9 \\
158-\end{array}$ & 8.94 & 35 & 7.1 & 59 & \\
\hline $\begin{array}{l}60 \\
65\end{array}$ & $\begin{array}{l}158- \\
180\end{array}$ & $\begin{array}{l}8.25 \\
7.76\end{array}$ & $\begin{array}{r}r_{4} \\
4\end{array}$ & $\begin{array}{l}6.3 \\
5.6\end{array}$ & $\begin{array}{l}39 \\
27\end{array}$ & \\
\hline 70 & I97 & $\begin{array}{l}7 \cdot 7^{6} \\
7 \cdot 4^{1}\end{array}$ & $187-$ & $\begin{array}{l}5.0 \\
4.96\end{array}$ & $\begin{array}{l}27 \\
2 \mathrm{I}\end{array}$ & \\
\hline 75 & I 74 & 7.03 & r8o & 4.25 & $77-$ & \\
\hline 80 & 142 & 6.45 & 83 & 3.68 & $33 I$ & \\
\hline 85 & 263 & 5.75 & 270 & 3.12 & 349 & \\
\hline 90 & 230 & 5.0 & 274 & 2.7 & 316 & \\
\hline 95 & $19 \mathrm{I}$ & 4.4 & 240 & 2.2 & 245 & \\
\hline 100 & 127 & 3.22 & 186 & I. 5 & 165 & \\
\hline 105 & 64 & 2.2 & 107 & I.O & II3 & \\
\hline Iro & 23 & $1.6 r$ & 61 & .44 & 76 & \\
\hline 115 & 9 & .29 & 29 & $.5-$ & 43 & \\
\hline
\end{tabular}




\section{Discussion. ${ }^{1}$}

Prof. Thomson:- If no one else cares to open the discussion I may make a few remarks. I called Mr. Thompson's attention to his statements in regard to the blowing out of the spark as expressing an erroneous idea in relation to the machine. This erroneous idea he will find expressed in Prof. Silvanus P. Thompson's Dynamo Electric Machinery, that the air blast in the Thomson-Houston three coil machine is for the purpose of blowing out the spark. That is not at all the case; it never was the case; and the air blast was introduced for no other purpose than to make it possible to run the machine steadily at high differences of potential with a commutator which could be freely oiled. It was found in the early experience with the macline that it was possible to construct a dynamo up to about twelve to fifteen arc lamps which would retain the normal working condition without flashing over, as it is called--short circuiting across the slots and the short circuit arc being carried around. But beyond that potential difference there was an eminent danger of its occuring, although a 25 light machine might run for an hour or an hour and a half without any flashing or short circuiting over. Of course the tendency to flash over, increased with the difference in potential. Now it was also desirable to run the commutator with a film of oil to freely oil the machine, and when the commutator was freely oiled the limiting potential which could exist without flashing was much lower. Even a 10 light machine might flash readily if there was a good deal of oil on the commutator. In the early days men would oil the commutator. It was almost impossib e to keep them from taking an oil can and squirting on the commutator. The Brush machines were also very sensitive to this same action, and their recommendations were very distinct as to what was to be done to oil the commutator-that is, take a rag and grease it with a little vaseline and touch the commutator lightly. If the commutator was thoroughly oiled there would at once be a flash. Another thing, the oil on the commutator of course diminished the wear, so that if there was any little roughening it was from cutting and making copper dust around the relieved commutator. I tried in the early days to get rid of the difficulty and did get rid of it by using condensers on the machine. I took the three coils and segments. I led our connections from each segment to a triple condenser. That preceded the development of the air blast. There were three coils in inductive relation. On a machine up to 6 or 8 lights I found I could actually obliterate the sparking at the tips of the brushes and the brushes could be moved quite a distance without provoking sparks while the machine was carrying its load. But I also found that the condenser was very subject to perforation. There were conditions arising which raised the po-

1. By Messrs. E. Thomson, Rice, Geyer and Nichols. 
tential enormously and I could under certain conditions get strong static discharges, (this is a very interesting matter indeed as looked at from the present standpoint in relation to alternating discharges.) With a coil of a single turn connected in the wire leading from the segment to the condenser coil, I could often get discharges of an eighth of an inch length snapping from one turn to the other; a discharge which refused to run around the coil-one in fact which went through the double insulation of wire and the air space between the turns instead of going a foot or two in the wire, and if it did not get a chance to do that, it was very apt to go through the condenser insulation. I tried to apply this principle to a much larger machine and I found I could not make the condenser live under those conditions. It would be perforated although it was a remedy for the flashing. The tips of the brushes were practically quiet. It did not fulfill the conditions in practice, so that it led to the trial of an air blast on the tips of the brushes, and the reasoning used in getting

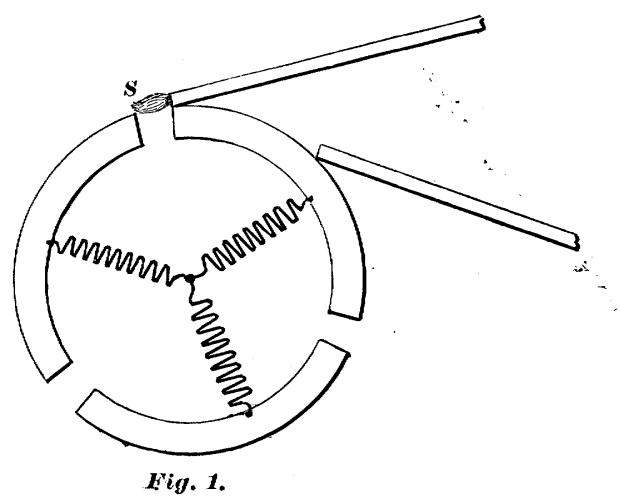

the air blast was this - to take a magnified image of the commutator brush and the slot (Fig. 1.) - that on the leaving of this segment there would be a small amount of current still fed from the segment to the brush, which would, as it were, tail off at $S$ and the sparks would be thicker at the brush and gradually thin out to a fine point and then stop. Then the segment would change polarity and go on to the other side. But naturally if the change of polarity was immediate on the cessation of that spark there might remain, as it were, from the spark, hot gas which would enable the discharge to take place in the opposite direction, and that was a flash which would be carried over as an are. My idea was simply to blow a cold blast of air-as it were to drive that spark away and insert, no matter how thin a layer of cold air before the reversal was accomplished and in that way to keep the insulation of the machine. That process is found effective even with a three coil commutator up to 3,500 or 4,000 volts, with the air pressure, of course, slightly increased as we rise. 
Now a few words in relation to the three coil machine, as to its development, may be of interest. The reasoning which led to the machine originally was somewhat like this: Here we have the old Siemens type of machine--a single coil machine with two segments (Fig. 2). It occurred to us that by taking that coil and dividing it in the centre and putting in another coil and slipping this segment around and making room for another, we would have a continuously acting arrangement something like a three cylinder engine, and we wonld have, as it were, a triple coil (Fig. 3). I do not regard these coils at all as separate coils. They are not separate coils. The system is a system working as a single coil system. Now it is not at all surprising that any measurement of potential, taking between the branching point of the divisions or the common point and any segment should show considerable fluctuation because the joint is only a point in the combined coil circuit. The equi-potential points or points of zero potential may slip back and, as it were, fluctuate- pass into

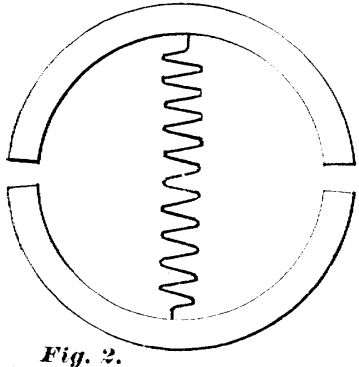

Fig. :

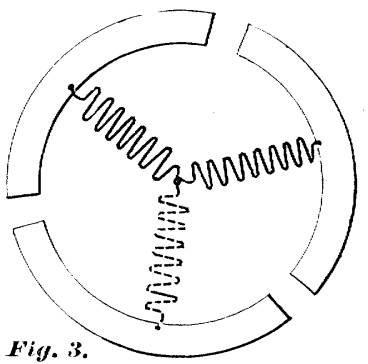

each coil, and do that a number of times in a revolution. Investigations show that it occurs twelve times. But what does it mean? It doesn't mean necessarily that the fluctuation is important. It means that the electrical condition of this junction of the three branches is changing several times in a revolution. The fact is that the activities of the coils are developed in nearly a sine curve, as I proved years ago-in fact in 1881-by the method of instantaneous contacts just then brought out. This was done by revolvin 2 a small, narrow segment and making contacts with a movable brush at successive positions. I got curves from the coils like that, and I got curves not only for the coils acting singly, but I got curves for the coils when acting together But it is proper to state that these curves, which were modified sine curves, were obtained with a machine working under what we may call now the disused condition of forward regulation. The three coil machine is capable of working in two ways. It may be regulated 
by the commonly practiced method, or it may be regulated by forward regulation as we term it (Fig. 4). We may put a brush here (Fig. 4.) and another one at a moderate angle generally about thirty degrees, (according to the field strength of the machine this angle becomes less or greater). If the field is very strong we have to diminish this angle because the transfer of current from one coil to the other takes place more briskly. These brushes are yoked together and during regulation which was the original way in which the machine was worked these brushes were moved forward by the regulator to diminish the electromotive force gradually. It was possible to work this machine not only to cut out every light without a spark, but it was also possible where two machines were run in series as was common at that time to take one machine with its brushes at the position of full load, take the other machine and by carrying the

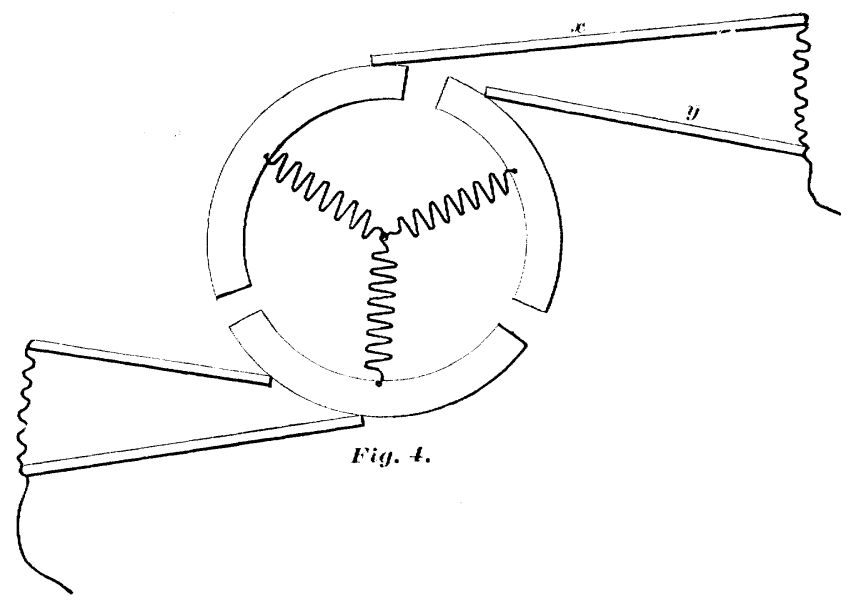

brushes around to actually convert it into a motor, so that every light in the circuit-say there were 20 lights - two ten light machines coupled in that way-every light could be taken out, and the two machines could be running, one feeding the other as a motor-the brushes having gone around without sparking to the opposite point-a very interesting thing indeed - and it was very curious to notice how the strain on the belts shifted as the transfers were made. While this method of operating the machine was undoubtedly a little more efficient than the present method; what we call the backward regulation, it did not give in all cases that kind of curve to the dynamo which was required for stability in the operation of all types of arc lamps. It was sometimes difficult to get the machines to be stable under some conditions, and even with changes in the proportioning, the quality of the iron would bother us with certain forms of lamps, although there were 
many machines constructed and operated in that way, but we had to do a great deal more adjusting in the factory than we did after adopting the backward type of regulation. We got, in other words, by the backward regulation a greater droop in the characteristic curve at the normal current point-a tendency, in other words, for the machine to become of itself a constant current machine. No matter what character or regulation of lamps existed on the circuit, whether they were differential or simply shunt lamps, that machine would take care of them and handle them. The former machine was sensitive to the lamps and sensitive to the adjustment of the lamps-differential lamps working much better than simple shunt lamps of course. When the shunt lamp was adopted it required that the droop in the characteristic be much more sudden. These considerations will throw some light on the general question which has been opened for discussion. [Applause.]

DR. GEYER:-I have always thought that this machine is the most unique and interesting of all the machines built. I am very glad that a study of it has been made in this manner by $\mathrm{Mr}$. Thompson. I should like to remark, however, that an exactly similar investigation was made as early as 1879 or 1880 on a Brush machine, which is one of the class called open coil. The apparatus was just the same, a ballistic galvanometer being used, but angles were taken only every ten degrees instead of every five degrees. The experiments were made more particularly to illustrate the action of any one particular coil or of two coils in series and finally. of the machine as a whole. ${ }^{1}$

Prof. Nichols:-It is very late, but I cannot refrain from saying that I hope that Dr. Geyer will try to get these belated results on the Brush machine published. I think it would be a very interesting thing at this day, when the method of instantaneous contacts has reached a development and has an important and recognized field-to publish measurements which were made at that early day, that we might compare those results with what are being obtained now. It seems to me that it is a most unfortunate thing that these results were not published in full in 1879 or 1880. It appears that this work must have been done before the appearance of Joubert's well known paper, and it seems to me it would be very well worth while to resuscitate these old results and to give them in full.

Mr. RICE:-In connection with the remark of Prof. Thomson, that the flashing of the commutator was due to the establishment of an arc across the segment through the hot gases, I think it would be interesting to state a fact which I believe is not generally known, but which we discovered at the works of the Thom-

1. Since taking part in this discussion, Dr. Geyer has met Prof. Thomas who participated in this investigation, and who has undertaken to prepare a paper for the Institute giving the details. For this reason Dr. Geyer's further remarks are omitted.-[Editor. 
son Houston factory while experimenting with large arc lights for government use, using currents of from 50 to 100 amperes, the potential difference being 50 volts and run in connection with a machine that would produce about 75 volts. We found we could turn out the light and allow the are to be completely extinguished for a full second; then switch on the current and the arc would be re-estabiished. This was done repeatedly, showing that the hot gas was sufficiently conductive to re-establish the arc where there was a difference of potential which could not have exceeded 75 volts. The same phenomenon has been observed by us subsequently in arcs using but ten amperes, although with such a small current, the time during which the current can be shut off with re-establishment of the arc, is much less.

During all these experiments the carbons were maintained separated the normal arc distance, $i$. $e$ : about one-sixteenth or three thirty-seconds of an inch for small currents, up to one-quarter or five-sixteenths of an inch for the larger currents.

Prof. Thomson:-I am glad attention has been called to that experiment for I have seen that case repeatedly in which you could turn off current by the switch and throw the current on again and the arc would re-establish itself, a complete dead space having existing between the carbous for some interval of time. I would say, calling attention to the paper of yesterday, that here we have an olservation which goes along with those of the paper very prettily - that here we have just the case of the stoppage and re-establishment, and the experiments just mentioned prove that the alternations might have been very slow indeed and with a considerable interval of interruption in the case of large arcs, without permanent extinguishment.

The Chamman :- If there be no further discussion, we will retur'n to the regular order of the prongramme, according to which the next paper is that of Dr. W. II. Wahl, of Plitadelphia, on "The Future of the Aluminium Problem from the Chemical Standpoint."

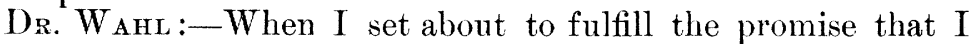
gave some time ago to one of the officers of your society, I was confronted with the difficulty of presenting anything that was new upon the subject of aluminium. I found, for example, that within the past few months several admirable papers have been presented on the subject, which treated it in almost all its aspects very thoroughly and leaving really very little that was new to be said on those particular phases of the question. I'rof. Richards, for example, in a lecture lately delivered before the Franklin Institute in Philadelphia, discussed the aluminium problem listorically in a most admirable manner, giving a resume of the state of the art down to the present time. practically covering this phase of the subject. Mr. A. S. Brown of your soc'ety presented, I believe, only a few weeks ago an excellent paper covering substantially the same ground, and giving facts and figures covering certain improved processes, and in March of the 
present year, I believe, Capt. Innt, of Pittsburgh, read a most admirable and exhaustive paper on the subject before the Boston Society of Arts, in which he discussed very thoroughly and instructively the prospective uses of the metal, especially in connection with its engineering application-a paper to which I would call your particular attention. In casting about to find some new phases of the subject it occurred to me that while the electrical process had had a number of champions, there had been very little said concerning the possibilities of the restoration of the chemical processes in the production of the metal in the future, and thinking it might possibly be a meritorious deed to take the part of the under dog, I concluded to present to you some of the possibilities from the chemical standpoint of producing aluminium cheaply.

Dr. Wahl then read the following paper: 